MATEC Web of Conferences 47, 03001 (2016)

DOI: $10.1051 /$ matecconf/20164703001

C) Owned by the authors, published by EDP Sciences, 2016

\title{
Modeling Zero - Inflated Regression of Road Accidents at Johor Federal Road F001
}

\author{
Joewono Prasetijo ${ }^{1, a}$ and W. Zahidah Musa ${ }^{1}$ \\ ${ }^{1}$ Faculty of Civil and Environmental Engineering, University Tun Hussein Onn Malaysia, 86400 Batu Pahat, Johor, \\ Malaysia
}

\begin{abstract}
This study focused on the Poisson regression with excess zero outcomes on the response variable. A generalized linear modelling technique such as Poisson regression model and Negative Binomial model was found to be insignificant in explaining and handle over dispersion which due to high amount of zeros thus Zero Inflated model was introduced to overcome the problem. The application work on the number of road accidents on F001 Jalan Jb - Air Hitam. Data on road accident were collected for five-year period from 2010 through 2014. The result from analysis show that ZINB model performed best, in terms of the comparative criteria based on the $\mathrm{P}$ value less than 0.05 .
\end{abstract}

\section{Introduction}

Malaysia has experienced a remarkable period of economic expansion and growth in population, economy, industrialisation and motorisation. Since then, the increase in population and motorisation led to a consequent increase in the number of road traffic accidents [1]. According to the survey obtained by iRAP (International Road Assessment Programme) on Malaysian road networks in 2007, the casualties for traffic accident include over 6,000 fatalities in a year. Over $60 \%$ of these fatal accidents happen on rural roads. Nearly half of all fatalities occur on federal roads and over a quarter on state roads. It was estimated about $2 \%$ of Gross Domestic Product (GDP), approximately RM 9 billion, to Malaysia's economy. In addition, traffic accident has become a major social-economic problem in Malaysia, and it is considered as main cause of death. Due to road accidents, result in annual economic cost of 9 billion ringgit to the nation economy. Numbers of fatalities reach over 6,000 people per year in road accidents nationwide. The amount has been increasing since 2003 and reached 6,872 for year 2010 while 21,397 suffer injuries. Traditionally, the simple risk measures such as observed accident counts, rates, costs, and other similar methods were used to target locations with a number of accidents exceeding a chosen threshold as hot spots [2]. Unfortunately, these measures have several shortcomings as discussed in a number of studies [2]. Alternatively, statistical modelling approach relate to the traffic safety are used for identification of hazardous locations. This approach is extensively used in traffic safety studies for identifying major contributing factors to crashes and injuries, establishing proper relationships between crashes and explanatory variables, and predicting crash frequency and injury severity. A generalized Linear Modelling technique such as Poisson

\footnotetext{
${ }^{a}$ Corresponding author : joewono@uthm.edu.my
} 
distribution was used and was found to be insignificant in explaining the effect of explanatory variables related to intersection geometry with accident count.

Generally Poisson regression analysis is the primary model which is use to find out the relation between independent variables and independent variable. The dependent variable must distribute as Poisson distribution. One of the assumptions of Poisson regression is the mean and variance must be equal, but actually most of the data will have the larger variance or over dispersion. The negative binomial regression is a method which can solve the over dispersion problem [3]. The problem outcome from the Poisson regression is when there are many zeros for dependent variable, the accuracy of the Poisson regression will be reduce, Zero-inflated Poisson regression (ZIP) is introduce to solve this problem [3]. The dependent variable in this study was accident data which occur to be excess zero. Thus, the zeros dependent variable depends on the other independent variables. Zeros dependent variable comes from the zero data that produce from data crashes. The motivation for the ZIP model is the model are comparable to those from fitting a NB regression model for general overdispersion [4], the potential under-reporting of vehicle accidents especially minor injury and property damage accidents [5], and [6] proposed to identifying effective factors on crash occurrence probability and prove the efficiency of Zero-inflated regression models against traditional Poisson and Negative binomials regression models. At the end of likehood ratio test, it seems that the ZINBDR model gave better results than NBDR model [7].

\section{Methodology}

\subsection{Poisson regression model, negative binomial model and zero inflation model}

The methodology, on which this research proposal is based, firstly treats the mean accident frequency at a site as an unknown quantity. Due to a random, discrete, and positive nature of crash data, count data modelling techniques such as Poisson and negative binomial (NB) regression models are used in such cases. The Poisson regression model has been traditionally considered as the starting point in modelling crash data, with assumption of the mean of crash counts being equal to its variance (that is, equal-dispersion) [8]. In the Poisson regression model, the probability of $n_{i}$ vehicle crashes occurring at a given road section $i, \operatorname{Pr}\left(n_{i} \mid \mu_{i}\right)$, can be estimated by

$$
\begin{gathered}
\operatorname{Pr}=\left(n_{i} \mid \mu_{i}\right)=\frac{\exp \left(-\mu_{i}\right) \mu_{i}^{n_{i}}}{n_{i}} \\
\mu_{i}=\exp \left(\sum_{j=1}^{M} \beta_{j} X_{i j}\right)
\end{gathered}
$$

where $\mu \mathrm{i}$ is the expected number of vehicle crashes at the given section, $X_{j}$ is a vector of covariates (road geometric, environmental and traffic information) and $\beta_{j}$ is a vector of estimable regression coefficients.

Unfortunately, much of the cases, the crash data produce the variance which is greater than the mean, well known as over-dispersion. The over-dispersion is a result of extra variation in crash means across sites which can be caused by various factors such as model misspecification, omission of important covariates, and excess zero counts. In this case, applying a Poisson regression model for vehicles crash data would result in underestimation of standard error of the regression parameters. Therefore, the negative binomial model will be introduced with

$$
\mu_{i}=\exp \left(\beta X_{i}+\varepsilon_{i}\right)
$$


where the $\exp \left(\varepsilon_{i}\right)$ is gamma distributed with mean 1 and variance $\alpha$ (the over dispersion parameter). By taking the unobserved heterogeneity of the Poisson mean to be counted, the following variance differ from the mean is introduced.

$$
\operatorname{Var}\left[y_{i}\right]=E\left[y_{i}\right]\left[1+\alpha E\left[y_{i}\right]\right]=E\left[y_{i}\right]+\alpha E\left[y_{i}\right]^{2}
$$

and the maximum likelihood function of the binomial regression model is shown as:

$$
L\left(\mu_{i}\right)=\prod_{i}^{N} \frac{\Gamma\left(\theta+n_{i}\right)}{\Gamma\left(\theta . n_{i}\right)}\left[\frac{\theta}{\theta+n_{i}}\right]^{\theta}\left[\frac{\mu_{i}}{\theta+\mu_{i}}\right]^{n_{i}}
$$

where $\theta$ is inverse dispersion parameter $(1 / \alpha), \Gamma($.$) is a value of gamma distribution, and \mathrm{N}$ is the total number of road sections.

In some cases, excess zeros in crash data exist and considered as a result of over dispersion. In this case, the NB model cannot be used to handle the over dispersion which is due to high amount of zeros. To do this, zero-inflation (ZI) models including Zero Inflated Poisson (ZIP) and Zero Inflated Negative Binomial (ZINB) models can be alternatively used. Both the ZIP and ZINB models assume that all zeros count come from two different processes: the process generating excess zero count derived from a binary model, and the process generating non-negative counts for vehicle crashes including zero values. As description of ZIP model, let $P_{i}$ as the probability of being excess zero for section $i$, and $\left(1-P_{i}\right)$ be the probability of crash counts derived from the Poisson distribution as it is given as

$$
P\left(Y=y_{i}\right)= \begin{cases}P_{i}+\left(1-P_{i}\right) \theta^{\mu_{i}} & y_{i}=0 \\ \left(1-P_{i}\right) \frac{\theta^{\mu_{i}} \mu_{i}^{y_{i}}}{y_{i} !} & y_{i}>0\end{cases}
$$

where $y$ is the number of vehicle crashes for section $i$ and $\mu_{i}$ is the expected crash frequency in section $i$ as a function of road section covariates, $\mu_{i}=\exp \left(X_{i} \beta\right)$. The probability of being in the zero-crashstate, $P_{i}$, is often fitted using logistic regression model, as follows:

$$
\operatorname{logit}\left(P_{i}\right)=\ln \left(\frac{P_{i}}{1-P_{i}}\right)=\gamma_{0}+\gamma_{i} Z_{i}+\ldots+\gamma_{N} Z_{N}
$$

where $Z=\left(Z_{1}, Z_{2}, \ldots, Z_{N}\right)$ is a function of some explanatory variables and $\gamma=\left(\gamma_{1}, \gamma_{2}, \ldots, \gamma_{\mathrm{N}}\right)$ is the estimable coefficients.

Similar to ZIP model, the probability density function for the ZINB given mean $\mu_{i}$, and dispersion parameter, $\alpha$, is given by:

$$
P\left(Y=y_{i}\right)=\left\{\begin{array}{cc}
P_{i}+\left(1-P_{i}\right) \frac{1}{\left(1+\alpha \mu_{i}\right)^{1 / \alpha}} & y_{i}=0 \\
(1-p) \frac{\Gamma\left(y_{i}+\frac{1}{\alpha}\right)\left(\alpha \mu_{i}\right)^{y_{i}}}{\Gamma\left(y_{i}+1\right) \Gamma\left(\frac{1}{\alpha}\right)\left(1+\alpha \mu_{i}\right)^{y_{i}+\frac{1}{\alpha}}} & y_{i}>0
\end{array}\right.
$$


The maximum likelihood method is used to estimate the parameters of the ZI models. In general, the probability of observing zero counts in ZI models is the sum of the probability of observing an excess zero in the first process and probability of observing a zero in the second process.

\subsection{Study area and data collection}

Study area of this research work was selected and considered from the south of Peninsular Malaysia after consulting with Malaysia road authorities such as Public Work Dept. (JKR), Malaysian Institute of Road Safety Research (MIROS), and Malaysia Royal Police. This study focused on F001 roadway which is Jalan Jb-Air Hitam. They will include those routes where high traffic volumes are present, large numbers of crashes occur and where a range of different road conditions are evident. The $\mathrm{R}$ software was used to analyze the data.

Table 1. A summary of some predictor variables.

\begin{tabular}{llll}
\hline Variable & Name & Variable & Name \\
\hline Dependent & Accident Crashes & Independent & Median width \\
Independent & AADT & Independent & No. of lanes \\
Independent & Traffic flow & Independent & Land use \\
Independent & Lane width & Independent & Access density \\
Independent & Shoulder width & Independent & $\begin{array}{l}\text { Horizontal } \\
\text { alignment }\end{array}$ \\
Independent & $\begin{array}{l}\text { Roadside hazard } \\
\text { rating }\end{array}$ & Independent & Vertical alignment \\
\hline
\end{tabular}

\section{Results and Discussion}

The empirical distribution of crash counts is plotted in Figure 1. The figures indicate that a peak of extra zeros which representing crash free exists. It confirms the presence of excess zeros in road accident crashes. This pattern is typical for most type of vehicle crash data. Moreover, the ratio of the variance to mean for fatal is 4.2 indicating the crash data is over-dispersed implying the poisson model do not adequately fit the overdispersed crash data. Then as alternative we use the better regression model which is Zero-inflated poisson and Zero-inflated negative binomial regression model.
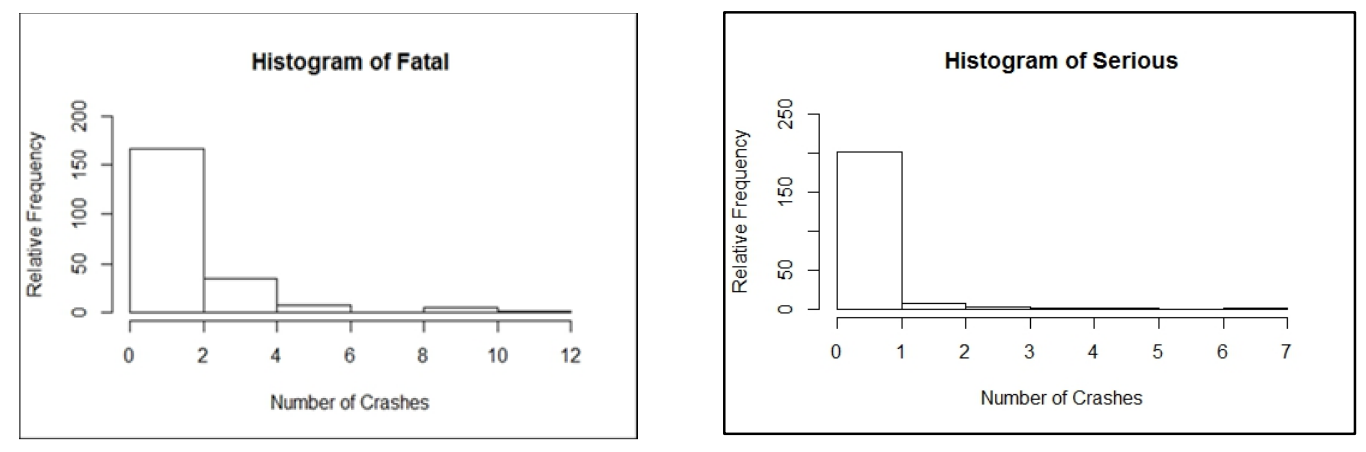

Figure 1. Histogram of observed accident crashes for F001 Jln Jb-Air Hitam during 2010-2014.

From Table 3, it shows the Poisson model coefficient. The less AIC (Akaike Information Criteria) the greater the model be more fitted. Hence from Table 3, AIC values for Poisson was 10154 which were high value compare to the AIC value for ZINB (727.2). The Poisson model assumes that the 


\section{IConCEES 2015}

variance of the dependent variable is equal to mean but in many applications, count data were found to show the over-dispersion [9]. The Poisson regression model is fit but when consider the raw data, there are many zeros which the ZIP will be approach.

Table 2. Result for showing existence of over dispersion in crash data.

\begin{tabular}{ccccc}
\hline Variables & $\begin{array}{c}\text { Standard } \\
\text { deviation [SD] }\end{array}$ & Variance & Mean & $\begin{array}{c}\text { Over dispersion= } \\
\text { [var>mean] }\end{array}$ \\
\hline Fatal & 2.057139 & 4.23181917 & 1.526 & Over dispersion \\
Serious & 0.8486408 & 0.72019126 & 0.3116 & Over dispersion \\
Minor & 3.475564 & 12.079547924 & 1.558 & Over dispersion \\
Wreckage & 125.4524 & 15738.29633704 & 70.24 & Over dispersion \\
\hline
\end{tabular}

Table 3. Poisson model coefficient.

\begin{tabular}{|c|c|c|c|c|}
\hline & \multicolumn{4}{|c|}{ Poisson } \\
\hline \multicolumn{5}{|c|}{ Pearson residuals: } \\
\hline \multicolumn{5}{|l|}{ Min } \\
\hline $1 \mathrm{Q}$ & \multicolumn{4}{|c|}{-13.2799} \\
\hline Median & \multicolumn{4}{|c|}{-5.8067} \\
\hline $3 Q$ & \multicolumn{4}{|c|}{-0.6374} \\
\hline Max & \multicolumn{4}{|c|}{5.1534} \\
\hline \multirow[t]{3}{*}{ AIC } & \multirow{2}{*}{\multicolumn{4}{|c|}{$\begin{array}{c}9.4189 \\
10154\end{array}$}} \\
\hline & & & & \\
\hline & Estimate & Std. Error & $Z$ value & $\operatorname{Pr}(>|z|)$ \\
\hline Intercept & $4.904 \mathrm{e}+00$ & $3.244 \mathrm{e}-02$ & 151.160 & $<2 \mathrm{e}-16$ \\
\hline Fatal & $-3.382 \mathrm{e}-02$ & $3.685 \mathrm{e}-03$ & -9.178 & $<2 \mathrm{e}-16$ \\
\hline Serious & $-7.509 \mathrm{e}-03$ & $8.825 \mathrm{e}-03$ & -0.851 & 0.394826 \\
\hline Speed & $-3.742 \mathrm{e}-03$ & $5.447 \mathrm{e}-04$ & -6.870 & $6.41 \mathrm{e}-12$ \\
\hline Volume & $2.015 \mathrm{e}-04$ & $5.288 \mathrm{e}-05$ & 3.810 & 0.000139 \\
\hline
\end{tabular}

Table 4. Zero inflated Poisson model coefficients.

\begin{tabular}{|c|c|c|c|c|c|c|c|c|}
\hline & \multicolumn{4}{|c|}{ ZIP } & \multicolumn{4}{|c|}{ ZINB } \\
\hline \multicolumn{9}{|l|}{$\begin{array}{l}\text { Pearson } \\
\text { residuals: }\end{array}$} \\
\hline Min & & -1.1967 & & & & -0.844 & & \\
\hline $1 \mathrm{Q}$ & & -0.8433 & & & & -0.749 & & \\
\hline Median & & -0.4249 & & & & -0.337 & & \\
\hline $3 \mathrm{Q}$ & & 0.4513 & & & & 0.3559 & & \\
\hline Max & & 7.0431 & & & & 5.9528 & & \\
\hline Log-like hood: & & -382.6 & & & & -359.6 & & \\
\hline & Estimate & Std. Error & $\begin{array}{l}Z \\
\text { value }\end{array}$ & $\operatorname{Pr}(>\mid z$ & Estimate & Std. Error & $\begin{array}{l}Z \\
\text { value }\end{array}$ & $\begin{array}{l}\operatorname{Pr}(>\mid z \\
\mid)\end{array}$ \\
\hline Intercept & 0.068389 & 1.988734 & 0.034 & 0.973 & 6.68847 & 0.00 & 0.00 & 0.00 \\
\hline Speed & $\begin{array}{l}- \\
0.024876\end{array}$ & 0.017027 & $-\overline{1.461}$ & 0.144 & -0.03952 & 0.00 & 0.00 & 0.00 \\
\hline Volume & 0.001118 & 0.001710 & 0.654 & 0.513 & 0.01719 & 0.04404 & 0.39 & 0.696 \\
\hline SW & $\begin{array}{l}- \\
0.381369\end{array}$ & 0.655635 & $-\overline{0.582}$ & 0.561 & -11.47283 & 0.00 & 0.00 & 0.00 \\
\hline LW & 0.271939 & 0.5223228 & 0.521 & 0.603 & -0.34308 & 0.00 & 0.00 & 0.00 \\
\hline
\end{tabular}

The absolute value of $\mathrm{V}$ is less than a threshold value such as 1.96 for 0.95 confidence level. From Table 5 the result for vuong was -1.93 which indicated that model 2 (ZINB) was preferred. Vuong test can indicate in any way if zero-inflated model is an improvement over standard a Negative Binomial regression [10]. It can compare between two model regressions. The vuong tests compare the zeroinflated model with an ordinary Negative Binomial model. In this analysis we can see that our test 
statistic is significant, indicating that zero-inflated model is superior to the standard Negative Binomial model. The less AIC (Akaike Information Criteria) the greater the model be more fitted. Hence in this analysis, Zero inflated Negative binomial was the most fitted model between the others due to the value of the AIC was 727.2. While for Zero inflated Poisson was 773.2, Negative Binomial was 734.16 and lastly Poisson was 10154. Good P-value for each independent variable was when P value was less than 0.05 . The result from Table 4 show that most of the p value for ZINB was less than 0.05 which is 0.00 .

Table 5. Vuong non-nested hypothesis Test-statistic.

\begin{tabular}{|c|c|c|}
\hline & Vuong z-statistic & p-value \\
\hline Raw & 0.8474188 model $1>$ model 2 & 0.198381 \\
\hline AIC-corrected & -1.9370687 model $2>$ model 1 & 0.026368 \\
\hline BIC-corrected & -6.6298185 model $2>$ model 1 & $1.6805 \mathrm{e}-11$ \\
\hline
\end{tabular}

\section{Conclusion}

This study is focusing on the Poisson regression and negative binomial model with many zero outcomes on the response variable. The zero-inflated Poisson regression model is more effective for many zero outcomes than Poisson regression. While, the zero-inflated negative binomial regression model is more effective for many zero outcomes than negative binomial regression. The application is work on the number of road accidents on federal road in the Johor, south of Malaysia.The zeroinflated negative binomial regression was used to find the relationship between dependent and independent variables when there are many zeros value in the dependent variable, where the relationship is the mixture between Negative binomial model and logistic model. This paper aimed to focus on developing a model which can properly handle stochastic nature of crash event. It also implies to find out the most relevant contributory factors at the hazardous sections and type of vehicle crashes. Lastly, this research can develop a statistical approach to estimate the safety performance of a road network in Johor federal roads. There are many further work to be done in this research (as the study is still ongoing) such as comparing the ZIP and ZINB model in terms of nested models, full probit and logit models, examine the coefficients of variables in different models and examine the diagnostic statistics of models to make it best performed to incorporate the models into traffic management systems.

\section{References}

[1] U. Radin, Updates of road safety status in Malaysia, IATSS Research, 29, 78-80, (2005).

[2] K. Geurts and G. Wets, Black spot analysis method: literature review, 7, 7-13, (2003).

[3] C. Pudprommarat, M. Khamkong and P. Bookkamana, Zero-inflated Poisson regression in road accidents on major road in the north of Thailand, IRCMSA Proc., 323-330, (2005).

[4] A.H. Lee, M.R. Stevenson, K.Wang and K.K.W.Yau, Modeling young driver motor vehicle crashes: data with extra zeros, Accident Analysis and Prevention, 34, 515-521, (2002).

[5] S.P. Miaou, The relationship between truck accidents and geometric design of road sections: Poisson versus negative binomial regressions, Accident Analysis and Prevention, 26, 471-482, (1994).

[6] E. Ayati and E. Abbasi, Modeling accidents on mashad urban highways, Open J. of Safety Science and Technology, 4, 22-35, (2014).

[7] M. Asrul and N.N. Naing, Analysis death rate of age model with excess zeros using zero-inflated negative binomial and negative binomial death rate: mortality AIDS co-infection patients, Kelantan, Malaysia, Procedia Economics and Finance, 2, 275-283, (2012). 
[8] M.H. Pour, J. Prasetijo, A.S. Yahaya and S.M.R. Ghadiri, Modeling vehicle-pedestrian crashes with excess zero along Malaysia federal roads, Procedia Social and Behavioral Sciences, 12181227, (2012).

[9] J. Garber, Stochastic Models Relating Crash Probabilities with geometric and corresponding traffic characteristics data, Research Report No. UVACTS-5-15-74, (2001).

[10]Q.H. Vuong, Likehood ratio test for model selection and non-nested hypotheses, Econometric, 57, 307-333, (1989). 